\title{
PELATIHAN OPTIMALISASI PENGGUNAAN SEARCH ENGINE
}

\author{
Rabini Sayyidati ${ }^{1)}$, Khairul Anwar Hafizd ${ }^{2)}$, Herpendi ${ }^{3)}$ \\ 1223) Jurusan Teknik Informatika, Politeknik Negeri Tanah Laut \\ Jl. A.Yani, Km 6, Ds. Panggung, Kec. Pelaihari, Kab. Tanah Laut, Kalimantan Selatan \\ ${ }^{1}$ Korespondensi penulis \\ e-mail: ${ }^{1)}$ rabini.sayyidati@gmail.com \\ ${ }^{2)}$ khairul.anwarhafizd@gmail.com \\ 3) herpendi@gmail.com
}

\begin{abstract}
Abstrak: Fenomena globalisasi memberikan dampak yang sangat besar bagi penyebaran informasi. Dewasa ini, masyarakat sangat mudah mengakses atau mencari informasi melalui search engine. Search engine sendiri adalah sebuah mesin atau software yang digunakan untuk mencari data atau file yang ada di internet. Meskipun search engine sudah umum digunakan hanya saja terkadang masih banyak orang yang tidak memanfaatkannya secara optimal, selain itu jenis search engine juga ada bermacam-macam. Pada pengabdian masyarakat kali ini, penulis memilih untuk memberikan pelatihan optimaliasasi penggunaan search engine dengan menggunakan browser google chrome. Peserta pengabdian kepada masyarakat ada 50 orang, yang terdiri dari 40 orang guru dan 10 orang staf tata usaha. Peserta merupakan guru dan staf dari Kecamatan Batu Ampar, kegiatan dilaksanakan di SMP Negeri 2 Batu Ampar. Panitia yang menghadiri kegiatan pengabdian ada 10 orang, terdiri dari 3 orang dosen, 2 orang laboran, dan 5 orang dosen. Pelatihan terlaksana dengan baik dan harapan peserta adalah kegiatan dapat berlangsung secara kontinyu sehingga dapat mencapai hasil maksimal.
\end{abstract}

Kata Kunci: Media Pembelajaran, Aplikasi, Microsoft Power Point

\section{PENDAHULUAN}

Seiring waktu teknologi mengalami perubahan besar, khususnya dalam bidang informasi dan komunikasi. Melalui teknologi internet, arus informasi semakin cepat, selain itu juga mempermudah mencari dan mengakses informasi terkini.

Biasanya masyarakat menggunakan search engine untuk mengakses infomasi yang ada di internet. Search engine ini sendiri ada berbagai macam jenisnya, seperti google, yahoo, MSN, bing, altavista, dll.

Pada kesempatan kali ini, penulis melakukan pengabdian kepada masyarakat di SMPN 2 Batu Ampar yang pesertanya adalah Bapak-Ibu Guru dan Staf dari seluruh Kecamatan Batu Ampar. Peserta pengabdian terdiri dari 50 orang, dengan rincian 40 orang guru, 10 orang staf Tata Usaha, sedangkan panitia pengabdian dari Politeknik Negeri Tanah Laut ada 10 orang, yaitu 3 orang dosen, 2 orang laboran, dan 5 orang mahasiswa. Penulis memilih untuk memberikan Pelatihan Optimaliasi Penggunaan Search Engine yang menggunakan browser google chrome. Google sendiri adalah software search engine yang paling banyak dikenal dan digunakan oleh masyarakat di Indonesia.

Tema ini sendiri dipilih karena meskipun banyak masyarakat yang telah tahu dan sering menggunakan search engine, akan tetapi mereka tidak menggunakannya secara optimal, sehinggga terkadang informasi yang diinginkan agak sulit untuk dicari atau bahkan dengan cara pencarian yang kurang tepat malah menimbulkan kesalahan informasi. 
Jurnal Mediteg

Volume 3, Nomor 1, Desember 2018

\section{METODE PELAKSANAAN}

Kegiatan pengabdian kepada masyarakat dilaksanakan dengan cara melakukan pelatihan langsung, dengan mengggunakan metode sosialisasi sekaligus workshop di SMPN 2 Batu Ampar. Pelaksanaan kegiatan dibantu oleh mahasiswa, sehingga setiap ada peserta yang kurang memahami materi maka akan dibantu oleh mahasiswa sehingga tidak menghambat materi yang disampaikan oleh tutor.

\section{TINJAUAN PUSTAKA}

A. Optimalisasi

Menurut KBBI (1995), optimalisasi berasal dari kata optimal yang artinya terbaik, tertinggi, sedangkan optimalisasi artinya suatu proses meninggikan atau meningkatkan ketercapaian dari tujuan yang diharapkan sesuai dengan kriteria yang telah ditetapkan.

Selain itu, menurut Poerdwadarminta dalam Ali (2014), optimalisasi adalah hasil yang dicapai sesuai dengan keinginan, jadi optimalisasi merupakan pencapaian hasil sesuai harapan secara efektif dan efisien.

B. Search Engine

Menurut Smitdev Community, dkk, (2015), search engine adalah sebuah program yang dijalankan untuk mengakases website dengan alat komputer dan berjalan dengan jaringan internet yang tersambung dan menjadi sebuah
p-ISSN : 2548-7655

e-ISSN : 2614-0489

sambungan untuk kalian yang mengoperasikan komputer untuk browsing dengan search engine yang telah tersedia pada komputer.

Menurut Lia Kuswayatno (2006), search engine adalah perangkat lunak yang digunakan untuk membuka website dengan cara menuliskan alamat situs yang dituju pada kotak address.

\section{HASIL KEGIATAN}

Kegiatan pengabdian ini melakukan beberapa tahapan yaitu acara di awali dengan melakukan pembukaan oleh Ketua Jurusan Teknik Informatika Winda Aprianti, M.Si. dan sambutan dari Kepala Sekolah SMPN 2 Batu Ampar sebagai tuan rumah. Setelah itu diberikan sosialisasi mengenai jenis-jenis search engine, dan software mana saja yang paling umum digunakan untuk mengakses infromasi.

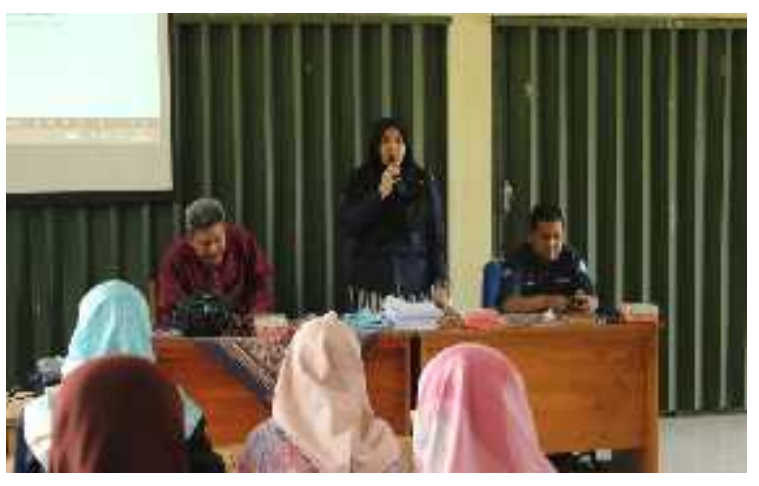

Gambar 1: Pembukaan yang disampaikan oleh Ketua Jurusan Teknik Informatika.

Pelatihan dilaksanakan di SMPN 2 Batu Ampar karena merupakan tempat yang paling mudah untuk dituju oleh tiap-tiap peserta yang merupakan perwakilan dari masing- 
Jurnal Mediteg

Volume 3, Nomor 1, Desember 2018

masing Sekolah Menengah Pertama di

Kecamatan Batu Ampar. Setiap peserta pelatihan diberitahukan untuk membawa laptop dan tetikusnya. Tutor menjelaskan fungsi-fungsi setiap fitur yang ada di software search engine, sambil mendengarkan peserta dapat praktik langsung. Selain itu, mahasiswa membantu mengajari peserta yang kurang memahami materi sehingga penjelasan dari tutor tidak terhambat. Peserta dipersilakan untuk bertanya dan berdiskusi mengenai halhal yang tidak dimengerti maupun jika ada fitur-fitur baru yang ingin mereka coba.

Hasil dari pelaksanaan pelatihan ini adalah, peserta lebih familiar meggunakan search engine dan dapat menggunakannya secara efisien dan efektif daripada sebelumnya. Peserta yang mengikuti pelatihan sangat antusias. Selain itu, penulis juga memberikan tips-tips untuk mencari tahu informasi yang valid, agar dapat menghindari berita-berita palsu atau yang kita kenal dengan berita hoax. Hal ini penulis lakukan agar dapat membantu peserta memfilter informasi yang mereka dapatkan dari internet.

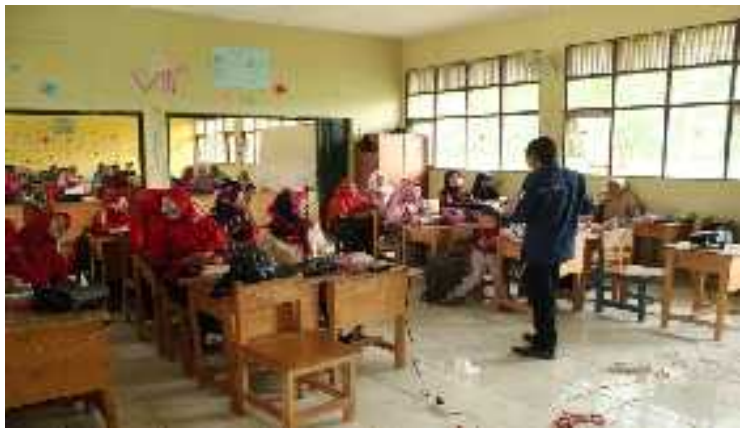

Gambar 2: Tutor memberikan pelatihan kepada peserta yang langsung praktik.
p-ISSN : 2548-7655

e-ISSN : 2614-0489

Setelah materi yang disampaikan oleh tutor selesai, peserta memberikan masukan mengenai materi apa saja yang mereka perlukan untuk pelaksanaan pengabdian kepada masyarakat selanjutnya.

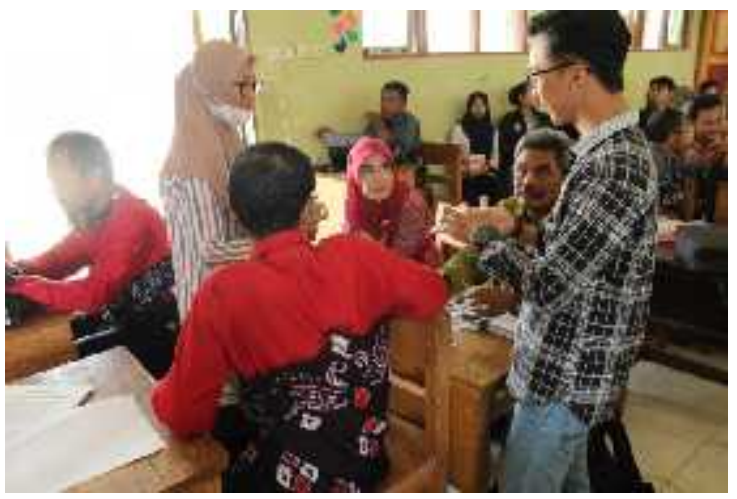

Gambar 3: Peserta dibantu oleh mahasiswa membuat presentasi dengan Ms. Power Point.

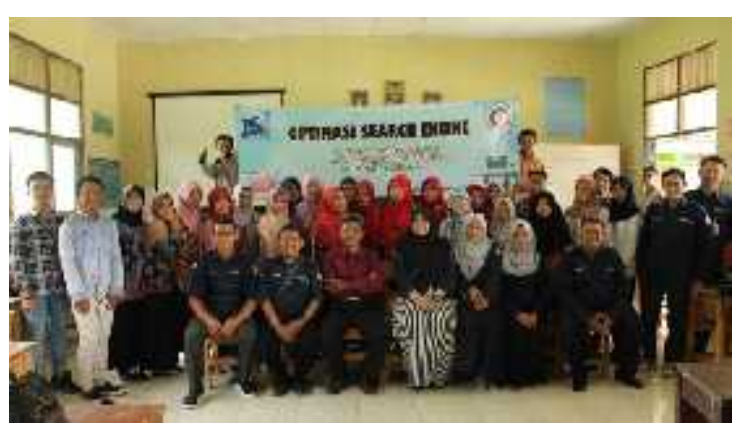

Gambar 4: Foto bersama setelah selesai pelatihan.

Pada akhir pelatihan, peserta dipersilakan untuk bertanya jika masih ada yang belum dipahami. Ternyata hanya sedikit peserta yang bertanya, setelah dievaluasi mereka sudah sangat memahami materi yang telah disampaikan.

\section{EVALUASI KEGIATAN}

Kegiatan berlangsung dengan baik dan lancar. Hanya saja ada beberapa hal yang 
perlu diperbaiki untuk kegiatan berikutnya.

Pertama, saat kegiatan akan mulai masih banyak peserta yang belum datang sehingga harus menunggu sekitar 45 menit. Hal ini menyebabkan kegiatan tertunda. Solusi kedepannya adalah pihak Politeknik Negeri Tanah Laut sebaiknya menekankan kepada pihak sekolah agar dapat mengkondisikan peserta sehingga bisa datang tepat waktu.

Kedua, sebagian peserta tidak membawa laptop sendiri, sehingga agak kesulitan ketika melakukan praktik. Hal ini dapat diatasi, karena panitia setiap panitia membawa laptop masing-masing dan bisa meminjamkan kepada peserta yang tidak membawa laptopnya.

Ketiga, setelah kegiatan selesai panitia meminta masukan kepada peserta mengenai apa saja yang harus diperbaiki dari kegiatan yang telah dilakukan. Peserta meminta agar kegiatan berlangsung secara kontinyu. Lewat masukan ini, panitia melakukan rapat mengenai materi untuk kegiatan selanjutnya.

\section{KESIMPULAN}

Kegiatan pengabdian kepada masyarakat berupa pelatihan optimalisasi penggunaan search engine yang diadakan oleh Jurusan Teknik Informatika, Politeknik Negeri Tanah Laut telah sukses dilaksanakan. Pelatihan ini membantu peserta meningkatkan pengetahuan dan kemampuannya dalam mencari dan

memasukkan informasi pada search engine dengan menggunakan browser google chrome.

Peserta pelatihan sebanyak 50 orang, terdiri dari perwakilan guru dan staf tata usaha dari seluruh sekolah di Kecamatan Batu Ampar. Panitia sendiri terdiri dari 10 orang. Kegiatan dilaksanakan di SMP Negeri 2 Batu Ampar.

Berdasarkan masukan dari peserta pelatihan, kegiatan ini diharapkan berlangsung secara kontinyu dengan materi yang juga saling berhubungan sehingga dapat terus membantu meningkatkan sumberdaya manusia khususnya guru dan staf pada Sekolah Menengah Pertama (SMP) di lingkungan Kabupaten Tanah Laut.

\section{DAFTAR PUSTAKA}

Ali, Muhammad Aidil. 2014. "Analisis Opimalisasi Pelayanan Konsumen Berdasarkan Teori Antrian Pada kaltimgps.com di Samarinda" dalam Jurnal Administrasi Bisnis, FISIPOL UNMUL. Vol 2, No.3.

Kuswayatno, Lia. 2006. Mahir dan Terampil Berkomputer. Jakarta: Grafindo Media Pratama.

Smitdev Community, dkk. 2015. Panduan Lengkap Berinternet. Jakarta: Gramedia Pustaka. 